Editorial

\title{
Os tumores odontogênicos ocorrem mesmo na clínica odontológica?
}

\author{
Nancy Alfieri Nunes
}

Dentre as lesões intra- ósseas deparamos com os cistos radiculares com muita frequência. Decorrentes de processo inflamatório e comprometimento pulpar, é de conhecimento dos cirurgiões-dentistas. Entretanto, quando se fala em tumores odontogênicos, talvez venha-nos à mente o odontoma, frequente, indolor, descoberto muitas vezes em radiografias de rotina. De fácil diagnóstico quando é o composto! ${ }^{1}$

Mas, e outros tumores derivados dos tecidos dentários?

O ameloblastoma é uma neoplasia benigna, relativamente comum (10 a $49 \%$ dos tumores odontogênicos) 1, 2,3, decorrente do epitélio odontogênico, que pode envolver tecidos moles (ameloblastoma periférico) ${ }^{4}$ ou tecido ósseo da maxila e mandíbula, com maior incidência na mandíbula, com variáveis formas e classificações histopatológicas, observado em pessoas jovens, segunda e terceira décadas de vida ou mais tardiamente ${ }^{1,2,3}$ Quanto aos aspectos radiográficos e imaginológicos podem ser uniloculares ou multiloculares, se assemelhando a lesão cística ${ }^{5,6}$ ou então sob a forma de múltiplas áreas radiolúcidas².

Os ameloblastomas apresentam diversos tipos histopatológicos e o diagnóstico permite tratamentos mais ou menos invasivos, visto que tendem a recidivar com frequência ${ }^{7}$.

Dos danos produzidos a cirurgias extensas e necessidade de reconstruções, nota-se que também há casos de sua correlação com carcinomas de células escamosas em mandíbula ${ }^{6}, 0$ comportamento dos ameloblastomas é considerado como mais ou menos agressivo ${ }^{7}$.

O diagnóstico deste tipo de tumor odontogênico é histopatológico e imunoistiquímico, quando se identifica positividade para CK19 e p634 e mutação de BRAF V600E; RAS, FGFR2 ou SMO'.

As variações histopatológicas, segundo a Organização Mundial de Saúde podem ser: sólido ou multicístico e unicístico ${ }^{5,7}$. Subtipos como o plexiforme, desmoplástico, folicular e acantomatoso, são descritos. Os unicísticos apresentam um comportamento menos agressivo ${ }^{3}$. As lesões em mandíbula são mais frequentes que na maxila. As recidivas estão associadas às mutações, mais frequentes também nessa região ${ }^{7}$.

\section{REFERÊNCIAS}

1 Ahire MS, Tupkari JV, Chettiankandy TJ, Thakur A, Agrawal RR. Odontogenic tumors: A 35-year retrospective study of 250 cases in an Indian (Maharashtra) teaching institute. Indian J Cancer. 2018 Jul-Sep;55(3):265-272. https://www.ncbi.nlm.nih. gov/pubmed/30693892

2 Nolabolu GRK, Mohiddin A, HIremathi SKF, Manyan R, Bharath TS, Raju Pr. Epidemiologica, study of odontogenic tumours: An institucional experience. J Inf Publi Health. 2017, 10:324-330.

https://www.ncbi.nlm.nih.gov/pubmed/27425795

3 Menditti D, Laino L, De Marco G, De Rosa A, Mellone $P$, Baldi A. Unicystic ameloblastoma of the mandible.2011, In Vivo, 25: 125-18.

http://iv.iiarjournals.org/content/25/1/125.full.pdf

4 Kaneko T, Nakamura S, Kawano R, Horie N, Shimoyama T. Peripheral ameloblastoma of the mandible: A case report. J Oral Maxilofac Surg Med Pathol. 2016; 28 (6):565-568.

https://www.sciencedirect.com/science/article/abs/ pii/S2212555816000090?via\%3Dihub

5 Iwase $\mathrm{M}$ et al. Hybrid Desmoplastic/Follicular Ameloblastoma of the Mandible: A Case Report and Review of the Literature. Case Rep Pathol. 2017; 1-6. https://scinapse.io/journals/2764691556?p=5

6 Hijioka $\mathrm{H}$ et al. Primary intraosseous squamous cell carcinoma arising from ameloblastoma of the mandible: A case report. J Oral Maxilofac Surg Med Pathol. 2015, 27(5):693-697.

https://www.ncbi.nlm.nih.gov/pmc/articles/ PMC3660158/

7 Heikinheimo K et al. The Mutational Profile of Unicystic Ameloblastoma. J Dental Res. 2019, 98 (1):54-60 https://www.ncbi.nlm.nih.gov/pubmed/30216733 